\title{
Federados, soldados y productores: la militancia sindicalista revolucionaria en el sector maritimo (1910-1924)
}

\author{
Laura Caruso \\ Conicet- IDAES/UNSAM - UBA \\ lauracaruso@gmail.com
}

En el barrio portuario de Buenos Aires, en 1910, nacía el primer sindicato marítimo perdurable que unificó las diversas categorias de trabajadores embarcados: la Federación Obrera Marítima (FOM). Con su estructura federativa, sus secciones diseminadas por el curso de los ríos interiores, sus miles de asociados y su enorme capacidad de paralizar la circulación de mercancías, este gremio se convirtió en, si no el más importante, al menos uno de los máximos animadores de la dinámica sindical en la Argentina de las primeras décadas del siglo XX. Al frente del mismo, en la ideología de sus militantes y en el contenido de su practica politico-sindical, se encontraba parte importante del sindicalismo revolucionario (SR) rioplatense, junto a otra fuerte presencia anarquista. Los trabajos que han abordado aspectos de la historia del SR en décadas pasadas lo han hecho de forma fragmentaria o como deriva de otros intereses (Bilsky, 1987; Godio, 1988; Bertolo, 1993; Del Campo, 1986; Rock, 1992). La indagación de las experiencias del sindicalismo en los diversos sectores del mundo del trabajo, así como su intervención política en coyunturas nodales de la historia obrera y su constructo ideológico-politico, son temas que se encuentran actualmente en el centro del interés de múltiples estudios, y con diversas perspectivas (Belkin, 2007 y 2013; Leyes, 2009; Bertolo, 2011; D’Uva, 2011; Monserrat, 2011; Koppmann, 2016)

Desde los inicios de la corriente sindicalista en el sector maritimo, las disputas y debates que el sindicalismo mantuvo con el anarquismo muestran la gestación de tradiciones comunes de lucha sindical, así como también resaltan las especificidades, algunas novedosas en su época, de las formas de construcción gremial a bordo del SR. Tales acciones vinieron a potenciar la fortaleza con la que ya contaba el grupo obrero marítimo, ocupado en un sector neurálgico del funcionamiento de la economía nacional y del mercado mundial, pilar del sistema de 
transporte de mercaderías agroexportables. Al buscar desentrañar y visibilizar los rasgos de las prácticas gremiales sindicalistas y las nociones que las sustentaron en su militancia a bordo, este trabajo apunta a, por un lado, establecer elementos susceptibles de comparación con otros sectores laborales con fuerte presencia sindicalista y, por otro, y fundamentalmente, dilucidar la propia dinámica y sustento de las formas de construcción gremial de esta corriente y sus derivas no solo temporales, sino también sectoriales y/o regionales. Retomando anteriores reflexiones, avanzamos ahora en nuevas consideraciones en torno al lenguaje, concepción y demandas de derechos por parte de esta corriente, aportando otra perspectiva a la nutrida historiografia sobre el debate de la huelga por la aplicación de la Ley de Jubilaciones de 1924. La prensa periódica de la federación, La Unión del Marino, es un pilar documental del análisis, sumada a la prensa de circulación masiva y de las corrientes de izquierda, junto a registros estatales como las publicaciones del Departamento Nacional del Trabajo.

\section{Una federación para los tripulantes del pais}

La conformación de una federación nacional de tripulantes, pocas semanas antes de los festejos y represión del Centenario, fue liderada por la corriente sindicalista, que compartía y competía por este lugar con militantes libertarios de fuerte presencia en la asociación de foguistas. $\mathrm{El}$ antecedente inmediato y clarificador de la creación de la FOM fue la huelga que, en forma paralela, separada y por reclamos de la misma indole, sostuvieron la Liga Obrera Naval Argentina (LONA) y la Sociedad de Foguistas Unidos, cercana al anarquismo. La protesta de los marineros del mes de enero y la de foguistas de fines de ese mes hasta marzo tensionó aún más la fragmentación en términos laborales y políticos, marcando un nuevo momento de crisis y recomposición en la organización gremial. En el clima de represión estatal a través de deportaciones y la utilización de la fuerza pública contra huelgas y manifestaciones, las protestas en el sector maritimo tuvieron un muy disímil desarrollo, dirección y resultado. La huelga de marineros y otros nucleados en la LONA, a fines de enero de 1910, reclamaba la actualización del acuerdo realizado en 1907 con la participación del poder estatal como mediador a través del Jefe de la Policía de la Ciudad, y tuvo pronta solución. ${ }^{1}$ En cambio, la sociedad de foguistas realizó un paro durante casi dos meses, debido a que las fuerzas estatales como Prefectura y Marina proveían

1. Boletín DNT, $\mathrm{n}^{\circ}$ 12, 31 de marzo de 1910; La Nación, 20 de enero de 1910. 
de personal a las empresas. Luego de la sistemática negativa a reunirse con cualquier instancia estatal, lograron parcialmente lo demandado. ${ }^{2}$

Ambos movimientos constatan, en su desarrollo fragmentario y dispar, dos estrategias sindicales que implicaban posicionamientos diversos frente al Estado y las formas de construcción gremial. ${ }^{3} \mathrm{El}$ ejercicio gremial de demanda y negociación mediada por algún organismo estatal encontró a los militantes sindicalistas de la LONA dispuestos y demandantes de incorporación de nuevas formas de resolución del conflicto obrero. Incluso en ausencia de una reflexión más sistemática y política sobre sus implicancias, los sindicalistas propiciaron la participación estatal en el campo laboral priorizando las mejoras inmediatas. De esta forma los dirigentes sindicalistas marítimos pasaron de la oposición teórica al Estado a la aceptación y apelación de su acción regulatoria, como se manifestó en la huelga señalada de marineros; tal apertura a la negociación, recurrente ya en los últimos años de la primera década del siglo, se tornó parte constitutiva de su práctica gremial en pocos años.

En ese tránsito surgió la FOM. Su creación fue el resultado de esa cambiante configuración político-gremial del sindicalismo y su despliegue en el sector marítimo. Esta aglutinó al conjunto de los trabajadores que tripulaban los buques mercantes en el país, por primera vez con verdadera proyección nacional. La federación consolidó diversos procesos previos en la construcción gremial a bordo, dando lugar a la ansiada unidad de todos los sectores tripulantes en un único organismo, comunión impulsada por los propios sindicalistas. De esta manera, la FOM inició un camino novedoso de construcción gremial, por su dimensión nacional, por la unificación de categorias laborales, por la recepción y vinculación con el Estado, y también por su búsqueda de control sindical dentro de la actividad. Fue a la vez síntesis y salto cualitativo de la experiencia gremial sindicalista con predisposición a la negociación con el Estado y hostil a la politica partidaria. En la noche del 5 de abril de 1910, destacando la importancia de la unidad de acción y organización de las diversas categorias laborales, se constituyó la FOM, federación de sindicatos y secciones que transitó así el paso de los gremios por oficios $\mathrm{u}$ ocupación al sindicato por rama de actividad de manera temprana y particular. Fueron los sindicalistas quienes propusieron y desplegaron la forma federativa, encontrando en ella un camino para superar la anterior fragmentación. Por pocas semanas estuvo al frente del nuevo

2. El rechazo a la mediación de cualquier entidad pública, no así a la negociación con las empresas navieras, se enmarca en las concepciones anarquistas y su negación doctrinaria a recorrer otros caminos posibles planteados en nuevos espacios de vinculación entre el Estado y el movimiento obrero (Suriano, 2000).

3. El análisis completo de la huelga y sus implicancias en Caruso (2016a, cap. 3). 
gremio Fernando Aldao, ${ }^{4}$ y luego, durante todo el período abordado, Francisco García, vinculado al anarquismo entonces y cuyo paso hacia el sindicalismo se consolidaría en los primeros años de la federación.

Como entramado inseparable y potente, el desarrollo de la FOM fue de la mano del periódico gremial, que brindaba materialidad y difusión a las ideas, valores, emprendimientos, organización y formación de los federados, con una clara orientación sindicalista. Así surgió La Unión del Marino $(L U M)$ convirtiéndose, no sin dificultades, en una herramienta para construir solidaridades, nociones e identidades, aspiración general de la prensa gremial en la ciudad, muy prolífica, por cierto (Lobato, 2009). Su mensaje aglutinador de una identidad gremial cercana a las ideas del SR impulsaba el despliegue del gremio por la amplia geografia nacional. Desde su nombre, el periódico reveló la centralidad que tenía la unidad como noción sindicalista, convocando desde alli a todo aquel tripulante a bordo, asi como a patrones, lancheros, maquinistas y oficiales, a una unidad de acción que superaba distinciones laborales, de oficios, calificaciones y tareas, orígenes y edades. Diversos militantes del SR escribieron en las páginas de $L U M$, y al mismo tiempo en varios otros periódicos de las centrales obreras o de la corriente sindicalista. En un mundo de palabras, consignas e imágenes, $L U M$ fue la voz de la FOM, constituyendo un elemento vital para la ampliación y consolidación de la federación, llegando a publicar unos dos mil ejemplares al inicio, y más de 12 mil hacia 1919. ${ }^{5}$

Los sindicalistas lograron verter sus nociones centrales en los estatutos de la federación, reforzando la centralidad y necesidad de la mentada unidad. Así, puede leerse entre los objetivos de la FOM la apuesta a "trabajar por la unidad del proletariado naval y terrestre para oponerlo como fuerza incontrastable a las arbitrariedades del capital, activar la organización y reorganización de los gremios navales en todos los puertos importantes del país, afirmar los sentimientos de fraternidad entre todos los obreros". ${ }^{6}$ Esta máxima se plasmó en prácticas diversas de solidaridad, acción conjunta y organización en todo el territorio. Su estructura federativa, sumando secciones por localidad a otras por categoria laboral, bajo la dirección de un Consejo Federal representado en Buenos Aires, es tal vez uno de sus rasgos más interesantes y, a la vez, un elemento central en la política gremial del SR. En dicha labor a bordo

4. Tanto Aldao como Francisco Soverano, Fermin Victoria y Eduardo Arraizaga, Iglesias, Castigliorisi y Guadalano, miembros de la nueva FOM, fueron expulsados el país ante la represión y la aplicación de las leyes de expulsión de extranjeros.

5. Boletin DNT, $\mathrm{n}^{\circ} 40$, febrero de 1919. Sobre la prensa maritima y sus formas de tratar la cuestión social ver Caruso (2017).

6. Boletín DNT, n ${ }^{\circ} 40$, febrero de 1919, p. 7. 
se destacaron militantes como Eduardo Pereyra, Fortunato Marinelli, Simón Larroche, entre otros, además de García. Como puede apreciarse en este dossier, esta fue una herramienta propia del SR aplicada a diversos sectores del trabajo. ${ }^{7}$ Las ventajas prácticas del esquema federativo en la construcción gremial radicaban en brindar una forma de rápida organización de secciones nuevas dispersas en el territorio y sumarlas a un todo en funcionamiento que conservaba su núcleo dirigente; permitía la ampliación y consolidación del gremio a la vez que preservaba un núcleo de militantes representativos del sindicalismo marítimo y forista del IX Congreso. En teoria, dicha estructura condensaba tanto la defensa de la autonomía y la autoorganización como la facilidad de sumar nuevas secciones y preservar un núcleo dirigente. Se diferenciaba de las federaciones libertarias y de su carácter ideológico doctrinario; la federación sindicalista resolvía problemas de la inmediatez organizativa, brindando una fórmula posible para extender la organización gremial y preservar su núcleo dirigente representado en el Consejo Federal. En este sentido, como en otros, los militantes sindicalistas actuaron como modernizadores de la estructura sindical, lo cual redimensiona la importancia de los cambios que imprimieron al movimiento obrero.

Ante la crisis económica y el impasse en la acción obrera en los años de la Gran Guerra, la construcción gremial sindicalista a bordo recurrió a otras instancias: la presentación de reclamos y expedientes ante la autoridad marítima por el incumplimiento de las leyes y reglamentos, exigiendo al Departamento Nacional de Higiene la correcta y minuciosa inspección de los buques, y sendas notas dirigidas al prefecto Blanco reclamando el cumplimiento de las ordenanzas reglamentarias de horarios y de tripulación mínima en cubierta y sala de máquinas. ${ }^{8}$ Tales instancias de la acción sindicalista, aunque con escaso resultado, constituyeron una forma alternativa y complementaria de construcción gremial.

Ya son conocidas las demandas y el alcance que tuvo el movimiento huelguístico a bordo en diciembre de 1916 con la huelga general marítima y su prolongación en la huelga parcial de marzo de 1917 (Caruso, 2016a, cap. 4). No está de más recalcar la consolidación organizativa, gremial y material que significó para la federación y para la FORA IX como núcleo de gremios sindicalistas. La FOM pasó de 2.000 a 12.336 miembros entre 1916 y 1918 sólo en Buenos Aires; sumó nuevas secciones en las costas interiores (Campana, Zárate, Rosario, San Fernando,

7. Otras federaciones sindicalistas impulsadas por la FORA IX fueron la Federación Obrera Petrolera, en 1917, la Federación Obrera Molinera en 1918, la Federación Postal y Telegráfica, la Federación de Empleados de Hospitales y Asilos Nacionales, el Sindicato de Obreros del Tanino y la Federación de Obreros del Calzado.

8. La Nación, 16 de mayo de 1913; La Razón, 13 de mayo de 1913. 
Santa Fe, Concordia, Concepción del Uruguay, Posadas y puertos de la costa patagónica). ${ }^{9}$ En las trece secciones que tenía en 1918, que reunían a más de 78 mil asociados, la FOM organizaba el embarco del personal en los buques de bandera nacional; cada vacante producida a bordo quedaba para los federados. ${ }^{10}$

En el caso de la dirección sindicalista de la FOM, esta expansiva organización supuso también la participación activa en la construcción y circulación de ciertas nociones y valores vinculados al propio trabajo a bordo y a los modos de ser "federado", esto es, ser hombre, trabajador y sindicalizado. En el proceso de gestación de una unidad federativa, el gremio marítimo sindicalista avaló y reforzó las jerarquías y la disciplina a bordo, así como el ejercicio de la autoridad, promoviendo la tolerancia y el respeto al superior desde el propio sindicato. A la vez, desde las páginas del periódico sindical se generaron y potenciaron ciertas nociones en torno al género que definieron valorativamente diversos rasgos para sus asociados, los Soldados de la Federación. De estos "virtuosos, valientes y heroicos hijos" de la FOM se esperaba su defensa incondicional, arrojada y permanente; enaltecidos y bravos, debían brindar su protección a la federación, representada -como el mar- en una forma maternal y dadivosa. ${ }^{11}$ Su fortaleza fisica y moral, su lucha, su espíritu unitario y militante, constituían atributos de su ser soldado del gremio. Aquel marítimo luchador que exponía su vida ante los peligros del mar, dando prueba de arrojo, solidaridad y tesón, pero también de responsabilidad y obediencia a las jerarquias y mandos, fue una figura clave enarbolada en cada conflicto, celebrada por las cartas de los socios, de sus mujeres y por colaboraciones de federados de otras secciones. ${ }^{12}$ Tales identificaciones, la del Soldado Federado centralmente, fueron estructurantes de y en la construcción gremial, reproduciendo en su apuesta por la construcción de una federación nociones diferenciadas y desiguales de género, y conservadoras de las jerarquías no solo entre hombres y mujeres, sino también a bordo, entre categorias y ocupaciones.

\section{Dominar el trabajo, construir la nueva sociedad}

Un elemento central de la militancia sindicalista lo constituyó el control del trabajo. Este fue sin dudas un rasgo significativo de la lu-

9. Boletin DNT, $\mathrm{n}^{\circ} 41$, abril de 1919 .

10. Boletin DNT, $\mathrm{n}^{\circ} 40$, febrero de 1919.

11. Boletín LUM, $\mathrm{n}^{\circ} 10,14$ de abril 1920; $\mathrm{n}^{\circ} 29,10$ de julio de 1920. Para un estudio de las nociones de masculinidad a bordo ver Caruso (2016b).

12. Boletín LUM, $\mathrm{n}^{\circ}$ 19, 29 de mayo de 1920, y n 16,19 de mayo de 1920. 
cha gremial maritima iniciada a fines de 1916, definido como el control efectivo, en la conformación e ingreso a la tripulación de una flota, de las condiciones de trabajo y permanencia en el puesto. En el ciclo 19161921, en pleno auge de la protesta obrera, no fue el único sector que demandó y construyó dicho control; sin embargo, fue allí, a bordo de las flotas mercantes, donde se dio más fuertemente el debate público y la confrontación capital-trabajo en torno a ese poder constituido.

Tal dominio del espacio y la dinámica laboral fue el eje de la construcción gremial sindicalista, y en el caso marítimo, ciertos elementos posibilitaron su existencia. Como se ha analizado, aparte de la centralidad del transporte naviero y la fuerte posición de sus trabajadores, el resto de los factores decisivos a la hora de explicar este control se vinculan directamente con la militancia sindicalista. La existencia de la federación nacional, la unitaria organización de categorias (marineros, foguistas, mozos) y secciones del interior fluvial, el ejercicio de la solidaridad reciproca de los gremios de la FORA IX y con los gremios marítimos de países limitrofes fueron determinantes en esta experiencia exitosa de control gremial. Las dos novedades que inauguró el año 1916 con la huelga general marítima y el nuevo gobierno nacional completan el cuadro explicativo, y se basan en prácticas sindicalistas de negociación y acción unitaria. El proceso de gestación y consolidación de una alianza con la oficialidad y sus centros fue clave en el ejercicio del control fomista (estos confeccionaban el rol de tripulación), contradiciendo en cierta forma la verticalidad de la organización laboral, no sus jerarquías. ${ }^{13}$ A la vez rebatía el interés de las empresas y las disposiciones legales, todo ello resultado de la politica gremial sindicalista a bordo. Tal transversalidad se expresó en novedosas formas de organización, como el Comité de Huelga conjunto, o el sistema de turnos de trabajo. El segundo elemento, de gran trascendencia, fue la particular vinculación establecida con el gobierno radical de Yrigoyen, quien recién asumía la presidencia de la Nación. La negativa a prestar ayuda a las empresas a través de personal de la Marina o Prefectura en tiempos de huelga, en esos años, hizo la diferencia para la protesta a bordo y el control fomista. Considerado por los sindicalistas como un derecho, sin embargo, el control del espacio laboral no obtuvo ningún tipo de reconocimiento legal, y ante la ausencia de un marco legislativo que protegiese y legitimase tal conquista, la única manera de sostenerla fue el permanente despliegue de la acción directa.

Las ideas sindicalistas, con un fuerte énfasis en el poder de los trabajadores como productores y en la "conquista" del barco como espacio

13. No cupo dentro de esta práctica ninguna impugnación al rol del capitán ni a los canales habituales para tramitar cuestiones frente a la autoridad a bordo. 
propio de construcción de nuevas relaciones y libertades, fueron la base de sustentación teórico-política del control del trabajo, considerado no sólo un ámbito de explotación sino también un espacio de capacitación, formación y creación de valores y criterios básicos para una futura sociedad sin clases. En el ideario del SR la producción era el lugar y el acto más alto de la personalidad humana, ámbito de la creación, el cual estaba dominado por el patrón y su derecho de organizar el trabajo y establecer la disciplina. En palabras de uno de sus representantes teórico-políticos, Julio Arraga:

Frente a esta autoridad que establece las condiciones de un trabajo impuesto, se levanta el sindicato para reclamar el derecho de organizar el trabajo libre, y es a medida que la libertad penetra en el taller emancipando a los trabajadores, que la sociedad también reconquista su libertad [...]. Todo el problema social está en la transformación del taller. Substituir gradualmente la autoridad del patrón por la organización voluntaria de los productores libres. (Arraga, 1910: 56-57)

Concebido como un derecho sindical, desde 1916 el control a bordo de la provisión y oferta de mano de obra no fue privativo ni de los marítimos, ni de nuestro país, más bien estructuró la relación trabajadores-empresa en otros sectores, puertos y latitudes donde la militancia sindicalista tuvo una fuerte resonancia: los obreros de la construcción naval del puerto de Buenos Aires, por ejemplo (Calello, Murmis y Marín 1969: 34). En ocasiones se concibió dicho control bajo el concepto de closed shop, sinónimo de cierre, aludiendo a experiencias históricas donde las organizaciones sindicales lograron controlar la provisión de mano de obra. Definido como un conjunto diverso de acciones y prácticas cuyo denominador común es que, para mantener su ocupación, el trabajador debe estar agremiado o adherir a una organización sindical determinada, donde la sindicalización se torna un elemento esencial para conseguir un puesto laboral (Oliveira Jr., 1995; Doeswijk, 2013), el closed shop parece acotado para interpretar cabalmente la experiencia del sindicalismo al frente de la FOM en los años de la Primera Guerra Mundial. El control sobre la organización y dinámica del mercado de trabajo, las condiciones de vida, y el ejercicio de un poder adquirido por la federación en sus relaciones con las empresas y las instituciones locales y nacionales rebalsa tal categoria, siendo mejor entendido como un ejercicio de control gremial por el monopolio o control del reclutamiento de la fuerza de trabajo, pero también por la definición de condiciones, dinámicas y relaciones de trabajo (Teixeira da Silva, 2003). El conjunto de las demandas obreras y el sustento teórico del SR aluden 
a un control sindical que excedia en mucho la contratación, incluyendo múltiples y diversas dimensiones de la vida y el trabajo a bordo, como las condiciones de alojamiento, la calidad y abundancia de la comida y la bebida, la compra de provisiones, uniformes, la organización de turnos y tiempos de trabajo, entre otros. En el planteo sindicalista esa lucha era la reivindicación de la dignidad obrera. La lucha en y por la configuración del espacio laboral a bordo constituía el núcleo de la politica gremial sindicalista, tanto en las construcciones de carácter más teórico-ideológico como en su práctica sindical, desplegada en las huelgas y acciones lideradas por la FOM (Caruso, 2016a: cap. 4).

De vital importancia, el control gremial del trabajo o de la producción fue incluido por las direcciones sindicalistas de la FOM y la FORA IX en sus estatutos. En el caso de esta última, su estatuto planteaba como objetivo: "Prepara a éstos (a los obreros) para asumir la gestión directa de la industria de acuerdo con el principio de que los instrumentos de trabajo pertenecen al trabajador". ${ }^{14}$ En 1917 , al modificar su carta orgánica, la FOM asumió como objetivo primordial conquistar el "derecho exclusivo de dirigir y organizar el trabajo social", para lo cual era necesario "coordinar la acción de clase de los sindicatos del gremio, a fin de llegar a constituir el trabajo libre de toda explotación capitalista". ${ }^{15}$ De esta manera, reafirmando el rol revolucionario del sindicato, los militantes del SR en la FOM dieron prioridad y real existencia a la construcción del control gremial, ya que consideraban que, organizados dentro de la fábrica, el taller o el barco, los trabajadores podian modificar los sistemas de trabajo y sustraer parcelas al dominio capitalista, para imponer nuevos elementos y condiciones más cercanos a sus intereses y comodidades, una mayor seguridad para su vida, más higiene para su salud, la concreción de mayores y mejores derechos. La sociedad reproducía la división en dos clases antagónicas, y en esta sólo el sindicato, al asumir las atribuciones de la empresa y organizar el trabajo exclusivamente con los productores/trabajadores, podría transformar las desigualdades existentes. El avance y penetración del sindicato en los lugares de trabajo podía traducirse en pequeñas expropiaciones parciales y diarias al poder de las empresas, las que sumadas daban lugar a una actividad emancipadora, el horizonte de la acción sindical. ${ }^{16}$ Asi lo concebia Fortunato Marinelli, militante sindicalista marítimo, que resaltaba el carácter emancipatorio del sindicato, capaz de terminar con la burguesía sin necesidad de derramar una sola gota

14. Boletín DNT, n 41, abril de 1919, p. 52. Artículo 2, inciso b, Estatuto de la FORA.

15. Boletín DNT, $\mathrm{n}^{\circ} 40$, febrero de 1919.

16. $L U M \mathrm{n}^{\circ}$ 54, agosto de 1919, "Acción Revolucionaria". 
de sangre, puesto que ya "se habian dejado de lado revoluciones de barricadas". ${ }^{17}$

Confrontando el poder patronal a bordo, el control fomista impulsado por los sindicalistas revolucionarios se mantuvo por varios años, de forma contundente hasta 1921, y con dificultades hasta 1924, definiendo condiciones de trabajo y de vida a bordo. Esta fuerte posición construida, de corte obrerista, con un planteo de vindicación del sindicato y su función social, no derivó ni acompañó un proceso de radicalización política ni enfrentó al SR con el poder estatal. Paradójicamente, cuanto más furibunda y contundentemente se movilizaron por el control a bordo, más se habilitaron espacios de vinculación y diálogo con el gobierno nacional, al tiempo que se consolidaba un lenguaje de derechos vinculados al trabajo y a la defensa de su libre organización.

\section{Legislación y derechos en la concepción sindicalista}

En el planteo político del SR es posible identificar pares opuestos que organizan la visión de la sociedad y su conflicto, organizada en binomios antagónicos: obreros productores-patrones, sindicato-partido, hecho económico-hecho político, justicia obrera-justicia capitalista, o derecho burgués-derecho obrero. La pugna entre estos pares estaba destinada a dirimirse en el terreno de la producción; así, dimensiones como el derecho, la ley y la justicia eran resultados del hecho económico fundamental, las clases y su lucha inherente. No existía ni justicia ni derecho universal, sino justicias y derechos según los grupos de interés (Arraga, 1910: 74-75). En la concepción sindicalista las nuevas leyes sociales reconocian una situación de hecho, que era el producto de la organización y la acción unitaria de los trabajadores. El derecho a huelga, a la libre organización, así como cualquier legislación que promocionase situaciones de mejora y seguridad laboral sería consecuencia de la acción de los sindicatos, impulsados por la necesidad material de los productores.

Dentro del conjunto de derechos reivindicados por los sindicalistas de la FOM se encontraba el derecho a la libre asociación. Estos, que no equiparaban necesariamente el reclamo de derechos con la exigencia de una ley particular que los avale, se movilizaron en contra de un proyecto de ley sobre asociaciones gremiales. Pocos meses después de la Semana Trágica, el sindicalismo fomista, junto a otros gremios y partidos, protagonizó una fuerte movilización por la defensa del derecho a la asociación libre y a ejercer la solidaridad obrera. El 28 de mayo de 1919 se presentó en la Cámara de Diputados un proyecto impulsado

17. LUM n ${ }^{\circ} 56$, octubre de 1919, "El quinto poder". 
desde la Comisión Especial de Legislación del Trabajo que reglamentaba la asociación sindical. El denominado "proyecto bodrio" o "proyecto mordaza" planteaba por primera vez en Argentina un sindicato único y responsable para todos los trabajadores de una actividad. En lugar de brindar un marco legal a los sindicatos existentes, dando asi garantias a su existencia y funcionamiento, el proyecto buscaba trabar la formación de nuevos sindicatos, su multiplicidad y competencia, y sus prácticas solidarias. La ley no dotaba de derechos sino que los vulneraba, reduciendo o anulando conquistas gremiales y materiales (Marotta, 1961: 270). El proyecto estipulaba que la existencia de un gremio debía ser declarada por decreto del Poder Ejecutivo Nacional, así como también establecía que los sindicatos reconocidos podrian constituir federaciones solo con aquellos de su mismo oficio o industria. El autor del proyecto, el diputado Sánchez Sorondo, ${ }^{18}$ sostenía la urgencia de la sanción de tal regulación de los gremios, motivada por el "estupor" de los argentinos ante los hechos de la "semana de enero" y de los anuncios anarquistas para los primeros días de mayo. Ante la amenaza revolucionaria, argumentaba, era acuciante "encauzar el "derecho colectivo" y respetar dentro del gremio trabajador el derecho personal". El proyecto soslayaba o directamente anulaba la posibilidad legal de solidaridades más amplias, intersectoriales, asumidas como "irresponsabilidades [...] que no responden a las conveniencias del trabajo, y que son, en definitiva, palancas preparadas para remover el orden social", ejercidas por parte de los gremios liderados por "agitadores profesionales". ${ }^{19}$

Tal vez como en ningún otro campo de la vida gremial, la concepción sindicalista defendía la libertad y la autonomía del derecho obrero a la organización, en oposición y clara exclusión de la intervención estatal. Precisamente el caso del derecho a organizarse libremente y a ejercer su solidaridad, reivindicado por el SR, se manifestó como demanda común con otras corrientes y gremios cuando, a mediados de 1919, y ante la presentación del proyecto de ley en el Congreso, se generalizó el repudio y la convocatoria obrera a movilizarse. Los gremios sindicalistas, y con ellos la FOM, concurrieron al congreso extraordinario convocado por la FORA IX a fines de junio, en el Teatro Verdi del barrio portuario (Marotta, 1961: 272). Allí, 255 delegados en representación de 155 sindicatos de la Capital y alrededores declararon al proyecto como "un

18. Matías Sánchez Sorondo, diputado por el Partido Conservador en 1918 y 1926, sería en años posteriores Ministro del Interior del gobierno de facto de Uriburu. Este personaje político clave del antiyrigoyenismo de matriz conservador nacionalista impulsó en la década del 30 el "proyecto de ley de represión al comunismo", representando una voz de las más radicalizadas del conservadorurismo antidemocrático (López Cantera, 2015).

19. Diario de sesiones, Cámara de Diputados, 28 de mayo de 1919, p. 164. 
atentado contra las libertades y derechos conquistados por la clase obrera organizada sindicalmente." Se volcaron entonces a organizar una gran demostración pública a lo largo del país, que tuvo lugar de manera simultánea en muchas ciudades, pueblos y puertos el 10 de agosto de 1919. Numerosas concentraciones, actos y mítines se extendieron por el territorio aquel día. Como no ocurría desde varios años antes, los gremios sindicalistas se movilizaron ese día; la FOM encabezó la columna sur desde la puerta de su sede de la calle Necochea de La Boca. Previamente se había desplegado un trabajo de propaganda intenso contra el proyecto, con la realización de cinco conferencias, entre julio y agosto, en la zona sur de la ciudad y con disertantes sindicalistas, la mayoría marítimos. La movilización fue entendida por la militancia sindicalista como un movimiento contra la ley y por el derecho obrero; la ley, sobre la cual se informaba, se debatía, se argumentaba, y fundamentalmente, se movilizaba, vulneraba el derecho propio, en lugar de consolidarlo. ${ }^{20}$ Así, el campo de la ley se constituía en un campo de disputa cada vez más intenso. El documento leído en el mitin de Buenos Aires concluia que el proyecto apuntaba, al prohibir las vinculaciones de diversos trabajadores de sectores y gremios y fragmentar al colectivo trabajador diferenciando entre trabajadores extranjeros de argentinos, a la disolución de la FORA IX y de toda central obrera. ${ }^{21}$

En todo el país, más de 240 mil trabajadores se movilizaron contra la ley, incluyendo Catamarca, San Juan, el Litoral y Buenos Aires. En la capital, la "colosal demostración" convocó a 140 mil obreros y familias, liderados por la FORA IX, el Partido Socialista y el Partido Socialista Internacional (PSI). La congregación en la Plaza del Congreso, al mediodía, se nutrió de seis columnas de manifestantes. A media tarde, estos se dirigieron a la Plaza San Martín y, tras 30 cuadras ininterrumpidas de manifestantes, realizaron un mitin donde tomaron la palabra los sindicalistas marítimos y foristas Francisco García y Senra Pacheco, los socialistas De Tomasso, Repetto, Bravo y Del Valle Ibarlucea, representantes de sindicatos autónomos y del PSI. Finalmente, el proyecto quedó trunco frente al repudio enérgico del sindicalismo en general, y el maritimo en particular. Este daba cuenta de los valores y derechos vulnerados por la ley, fortaleciendo las nociones de organización sindical autónoma, e instalando ciertos sentidos políticos del derecho obrero. Al mismo tiempo la movilización de agosto de 1919 mostró cómo el SR impulsó simultáneamente y de forma imbricada la lucha por derechos

20. $L U M, \mathrm{n}^{\circ} 54$, agosto de 1919 , p. 4.

21. LUM, $\mathrm{n}^{\circ} 55$, septiembre de 1919. Precisamente el proyecto atacaba aquello que un funcionario del DNT caracterizaban como "el nuevo poder", la central obrera y el ejercicio de la solidaridad. Boletín DNT, $\mathrm{n}^{\circ} 41$, abril de 1919, p. 75. 
vulnerados o potenciales, y la negociación y diálogo con el Estado en distintas instancias y momentos.

Finalizado el ciclo de protesta con la represión a la huelga general de 1921 (Horowitz, 1995), que supuso para el gremio maritimo una derrota irreparable cuyas consecuencias se verian con mayor claridad en 1924, la recomposición de las organizaciones sindicales incluyó la formación de una nueva central obrera, la Unión Sindical Argentina (USA), a la cual adherian los sindicalistas de la FOM. A la par se dio el cambio de gobierno con la asunción de Marcelo T. de Alvear que, coincidente con una baja en la conflictividad obrera, iniciaria un camino en función de la sanción legal de algunos acuerdos y condiciones surgidos en la etapa previa (Falcón y Monserrat, 2000). En este nuevo escenario, todas las variables que sustentaban la politica gremial del SR parecian en jaque. La crisis mostró con mayor claridad y potencia las diferencias y oposiciones políticas que desembocaron en una dificil situación interna. La federación como forma de organización no parecía garantizar la autonomía real de las secciones, afrontando así un fuerte cuestionamiento, en momentos donde precisamente estaba en disputa y definición al interior del movimiento obrero qué modelo sindical prevalecería. Con esto, el control gremial se encontraba amenazado por la presión de las empresas a los oficiales, por iniciativas como el proyecto de ley o abiertamente por la represión estatal y la organización patronal de brigadas de trabajadores.

En ese contexto parece necesario indagar las nociones de la ley y el derecho, así como una concepción más global del Estado y la sociedad que el sindicalismo vernáculo sostuvo en los años 20. Si hoy conocemos la política de acercamiento acrítico de la dirigencia sindicalista al Estado en el caso marítimo, esto no invalidó su intento por sostener algunos de sus posicionamientos ideológicos. Así lo muestra la polémica abierta en el año 1922 con La Fraternidad, el particular gremio ferroviario, acerca de la personería jurídica para los sindicatos. Por debajo de una serie de acusaciones pueden visibilizarse las nociones criticas del sindicalismo hacia la personería jurídica. Si bien gremios aliados a la FOM contaban con tal personería, como los maquinistas y capitanes, no eran la federación ni su sector sindicalista dirigente partidarios de tal demanda, a la cual consideraban inútil a la hora de garantizar mejores condiciones o derechos. Los sindicalistas de la FOM contraponían a la personería jurídica la personería sindical, y colocando su caso como ejemplo, entendían así que en la coyuntura de confección de los decretos de oficialización de 1919, tanto el Estado como los armadores habían dado lugar y voz a la FOM no por su personería jurídica, de la cual carecía, sino por el hecho de su potente organización y su potencial acción, su personería 
sindical, garante de sus derechos. ${ }^{22}$ Así, Francisco García respondía al gremio ferroviario sobre la aceptación del arbitraje estatal en 1916; esta no significó esencializar la admisión del Estado dentro del campo obrero; sólo dotó a la federación de un medio para imponer condiciones. Sostenía García que la reunión mantenida con el presidente Yrigoyen en aquel momento había sido resultado de una exigencia de derechos respaldada con la acción, y no de un pedido de protección. Allí podían los trabajadores federados mostrar su personería sindical, de la que carecían maquinistas y capitanes. El dirigente del SR denunciaba el "corporativismo legalitario" de La Fraternidad, contrastante con la acción directa marítima. En esta concepción sindicalista, la personería jurídica se evidenciaba infructuosa frente a la competencia gremial en el movimiento obrero y frente al ataque patronal, cada vez más virulento. ${ }^{23}$

Para el año 1924, el debate en torno a la ley de jubilaciones fue iluminador acerca de las nociones sindicalistas de la ley y los derechos, y así se evidenció en la FOM. ${ }^{24}$ Tales posicionamientos y sus debates respecto a esta ley en particular pusieron en juego ciertos sentidos sobre las leyes en general, acciones y posiciones frente al Estado, alianzas y estrategias. El lugar extenso que este debate ocupó en la prensa fomista, sobre la ley en general, la jubilación en particular, el derecho a la misma y sus derivas, es un valioso acervo donde bucear en los sentidos sindicalistas de la ley y el derecho. Este debate se inició aún antes de que las centrales obreras tomaran nota, ya que en agosto de 1922 el diputado radical Leónidas Anastasi presentó en la Cámara de Diputados un proyecto de Jubilaciones, Pensiones y Retiro para la Marina Mercante. Entre otros elementos, este proponía como origen de los fondos aportes mensuales que debian realizar los trabajadores, un $5 \%$ aquellos que cobraran más de \$100; quienes estaban por debajo de esa cifra aportarian un $2 \%$; sumando el aporte de un mes de salario de quienes tenían menos de 15

22. $L U M, \mathrm{n}^{\circ} 87$, julio de 1922 , p. 1 .

23. $L U M, \mathrm{n}^{\circ} 99$, julio de 1923 , p. 2.

24. Quienes estudiaron la huelga contra la ley 1189 han privilegiado diferentes aristas del fenómeno. Si por un lado Joel Horowitz la consideró un episodio valioso para examinar fortalezas y debilidades del gobierno de Alvear y su politica hacia los trabajadores, Cristian Aquino en cambio muestra la campaña de agitación y la huelga como momento de resurgimiento de componentes anticapitalistas dentro del SR (Horowitz, 2001; Aquino, 2007). El repudio sindical y de las corrientes políticas de izquierda tomado como un todo unívoco es desbrozado por el análisis de Luciana Anapios, quien muestra el mosaico de posiciones y matices ocultas tras la supuesta oposición monolítica del anarquismo, mostrando cómo la ley y su contexto promocionaron ciertas visiones ni homogéneas ni meramente doctrinarias, permeadas por un consenso incipiente a la intervención del Estado entre los trabajadores y sus organizaciones (Anapios, 2013). 
años de antigüedad, y de dos meses los que excedieran tales años. La Caja de Jubilación y su administración estarian a cargo de un cuerpo mixto compuesto por tres representantes empresariales, tres gremiales y un presidente designado por el gobierno y aprobado por el Senado. Tal proyecto fue puesto en consideración del gremio, lo que impulsó un intercambio, deliberación y debate, que se amplió al conjunto de los trabajadores con el proyecto gubernamental de la Ley de Jubilaciones, sancionada un año y medio después, posteriormente suspendida y derogada tras la huelga general de julio de 1924 .

Por diversos motivos, la ley generó resistencias y oposiciones; algunos trabajadores directamente llamaban a oponérsele sin reparos. Otros, como Francisco García y otros miembros del SR defendían la necesidad de discutir la ley, aún en oposición. Esta dispar argumentación mostraba una polifonía de ideas y argumentos, signo del campo tenso y difuso de la injerencia estatal y los derechos de los trabajadores. Precisamente Garcia, en diciembre de 1922, reiteraba en torno al proyecto de ley jubilatoria la incapacidad de la misma, y alentaba su debate y estudio para realizar una propuesta superadora. Los sindicalistas planteaban que esperaban todo de la acción sindical y nada del parlamentarismo, pero el debate sobre la ley mostró que las expectativas en este último existían. La ley, reformulada y apropiada, debía ser puesta bajo la órbita de los propios intereses mediando la acción directa, aun siendo "una de las tantas tretas del capitalismo para hacer creer que se preocupa por la felicidad de sus víctimas". ${ }^{25}$ Al no surgir de la iniciativa sindical sino de los "cabildeos partidistas" del radicalismo, la ley se hallaba bajo sospecha y era considerada ajena al mundo obrero de a bordo. Así, desconocía por completo el mundo laboral embarcado, previendo, por ejemplo, treinta años de trabajo para acceder al beneficio. Ningún trabajador alcanzaba tal antigüedad, menos aún sin interrupciones; mediaban meses de desocupación forzada, que se reiteraban por más de un período. Acumular treinta años de trabajo implicaría el doble de años para jubilarse, algo utópico para un marinero o foguista, cuya expectativa de vida era menor; tras quince años de trabajo un tripulante era un "hombre inutilizado", un "desecho". ${ }^{26}$

Tras la promulgación de la ley de jubilaciones, en febrero de 1924, el mismo García envió una carta al presidente Alvear comunicándole que los trabajadores de la FOM habian rechazado en asamblea y por unanimidad la ley, por considerarla perjudicial, e iniciarian una etapa de gestión ardua por su suspensión y modificación. Los descuentos previstos al salario eran particularmente perniciosos, ya que, en el caso del

25. $L U M, \mathrm{n}^{\circ} 99$, julio de 1923, p. 5.

26. $L U M, \mathrm{n}^{\circ} 94$, febrero de 1923, p. 3. 
primer buque en zarpar, los salarios de la tripulación se habian reducido en un $18 \% .{ }^{27}$ Pero la misiva al presidente también anunciaba que los trabajadores maritimos no eran adversos al principio de la jubilación, sino que debian rediscutirse sus formas y fundamentos, quedando el costo totalmente a cargo de las empresas. Y concluia: "Sr. Presidente, consideramos la jubilación como un derecho, máxime los tiempos que corren, que son de revisión de valores, creadores de nuevos derechos consecuencias de luchas gigantescas, sostenida por la clase productora".

En la asamblea citada, realizada el 20 de enero, se desarrolló un intenso debate sobre si la ley presentaba "fallas" o su basamento mismo era equivocado. Allí se esbozaron divergencias en las nociones propias del SR y su disputa con otras corrientes. Mientras el maritimo Ojeda afirmaba que toda ley constituía una barrera impuesta por el Estado y las empresas a la acción obrera, Antonio Aguilar decía: "pienso de que el obrero una vez que haya forjado cierto tiempo su vida en la usina del trabajo, debe haber un derecho que le ampare en su vejez". Aunque crítica, esta visión consideraba la modificación de la ley como la única salida para evitar que se vieran "como se ven hoy tirados por las calles a cientos de hombres vencidos por el trabajo". Otra carta denunciaba que la ley, "lejos de proteger al obrero, le ocasiona una difícil situación, en espera de ser "algún dia" jubilado": tal como los lobos no hacen leyes para proteger a los corderos, la ley denigraba al productor. Francisco Yodas, desde el territorio del Chaco, opinaba que la aplicación de la ley significaría la muerte de los sindicatos, creando una "fábrica de borregos serviles". ${ }^{28}$

Declarada la huelga general contra la llamada "ley aborto", "calote", robo o infamia por el sindicalismo, su debate en el sector maritimo tuvo severas consecuencias para la FOM y su alianza estratégica con otros sectores, como los capitanes de bordo, quienes apoyaron la ley (Horowitz, 2001). El debate en torno a esta ley, entre muchas otras cuestiones, permite pensar los contrastes o posibles desfasajes entre las ideas doctrinarias que sustentaron la práctica gremial de la corriente sindicalista y la construcción gremial concreta, así como también muestra las variadas consideraciones entre los trabajadores afiliados y las disputas del sentido y razón de la ley. Entre la derogación de la ley burguesa y la búsqueda de bienestar en la vejez sobre la base de los aportes patronales, la concepción de la ley y los derechos abonada por el sindicalismo mostró una pluralidad de sentidos, estableciendo la lucha por estos como parte de su politica, colocando la demanda de derechos por sobre la ley. Con esto, favoreció entre los federados y sus

27. $L U M, \mathrm{n}^{\circ} 105$, febrero de 1924 , p. 1 .

28. $L U M, \mathrm{n}^{\circ} 105$, febrero de 1924, p. 2. 
familias la apropiación y uso de un lenguaje en torno a los derechos y las leyes como horizonte posible y deseable, cuando no como campo de disputa. En los intersticios de la declaración de la huelga general contra la ley por la USA y las corrientes de izquierda, y de la propia huelga marítima, puede apreciarse la capacidad de los SR de incorporar y procesar nuevas instancias de construcción gremial, no carentes de debates y resistencias.

\section{Comentarios finales}

En los años que van desde la creación de la federación marítima, en 1910, hasta la ruptura de la alianza con la oficialidad, a mediados de 1924, la militancia sindicalista revolucionaria al frente de la organización gremial desplegó una construcción sindical particular, que enfrentó a un mundo laboral fuertemente fragmentado, al cual contrapuso la construcción de una unidad de secciones y categorias, y una transversalidad en la acción de protesta, sumando desde 1916 a capitanes y personal jerárquico. Si bien no cuestionó tales jerarquías, desarrolló un poder gremial de peso, tanto en el espacio laboral de la navegación, como en las disputas al interior del movimiento obrero y, sobre todo, frente a las patronales y el Estado. A través de un sindicato único nacional, de estructura federativa, y de la consolidación del control del trabajo a bordo, el SR definió una experiencia de organización y acción gremial que, si bien no fue exclusiva del sector, encontró allí una manifestación amplia y decisiva en varios sentidos. Tal vez lo más significativo fue la base de sustentación y representatividad que la forma de federación nacional le dio a la hora de negociar y dialogar con el Estado Nacional a través de múltiples instancias, cuya presencia e intervención fue reclamada por su dirigencia sindicalista.

Si la forma federativa y el control sindical del trabajo formaron parte de la concepción, orientación y práctica común y general de los sindicalistas en la militancia gremial, en tanto cultura política del movimiento obrero, la alianza con la oficialidad, el fluido diálogo con el Estado y ciertas nociones como la de soldado federado pueden considerarse propias de los avatares de esta corriente en el sector marítimo. Esta potente noción identitaria generizada, el soldado federado, reforzaba el poder gremial junto a ciertas nociones de masculinidad. Tales definiciones del sujeto trabajador a bordo apuntalaban la labor gremial, al tiempo que reafirmaban las jerarquías y nociones tradicionales de género. En el cruce de una multiplicidad de subjetividades, estos soldados federados eran a la vez productores que, mediante la organización, buscaron controlar el trabajo a bordo: su lugar, sus condiciones, el ingreso y la organización laboral. Destacar la centralidad del control sindical en la 
estrategia gremial del SR permite identificar especificidades dentro de un repertorio común de acciones de lucha con otras corrientes actuantes en el movimiento obrero, resultado de una tradición obrera en constante desarrollo. Al mismo tiempo, puntualizar las formas de la politica desplegada por el SR en este sector permite superar tales generalidades, visibiliza las capacidades organizativas e iniciativas propias de estos militantes. Las ideas que las sustentaron de unidad y unicidad gremial fueron de la mano de una demanda de derechos considerados propios del sujeto trabajador y solo asequible en su acción colectiva. Esto muestra un universo gremial donde las figuras del soldado federado, el productor y el sujeto de derechos fueron claves en las formas de la política gremial sindicalista, su militancia y organización. En múltiples oportunidades, de las cuales se ha revisado aquí la lucha y movilización por el derecho a la libre organización en 1919, el debate sobre la personería jurídica y sobre la Ley de Jubilaciones en 1924, la forma de constituir demandas gremiales por parte del SR fue en torno a la noción de derechos, con una lectura particular y clasista de la sociedad y de la ley. Los derechos reclamados eran considerados producto de la acción obrera, no necesariamente asociados a la existencia de una legislación específica. Si bien esto fue así, en el tránsito que va desde la lucha contra el "proyecto bodrio" y la negativa a la Ley de Jubilaciones tal como habia sido votada, se evidencia una reconsideración por parte del sindicalismo en la asimilación de la ley y la participación del Estado en la concreción de los derechos, habilitando su debate y desplegando sendos argumentos sobre la necesidad de discutir una ley para el retiro laboral que colocaba el campo de la ley en un horizonte de disputa y negociación con el Estado, algo novedoso para esta corriente, ya que, ni en su vínculo con el Estado desde 1916, ni en su control del trabajo a bordo, ni en ninguna instancia de su construcción gremial previa en el sector de la navegación había demandado su sanción mediante la ley.

\section{Bibliografia}

Anapios, Luciana (2013), "La ley de jubilaciones de 1924 y la posición del anarquismo en la Argentina", Revista Historia del Derecho, $n^{\circ} 46$, Buenos Aires.

Aquino, Cristian (2007), "Izquierda y movimiento obrero: estrategias y discursos del sindicalismo revolucionario a propósito de la ley de jubilaciones de 1924", ponencia XI Jornadas Interescuelas de Historia, San Miguel de Tucumán.

Arraga, Julio (1910), Reflexiones y observaciones: sobre la cuestión social, Buenos Aires: Librería La Facultad,

Belkin, Alejandro (2013), "La crítica del sindicalismo revolucionario argentino 
al parlamentarismo (1905-1912)", Archivos de historia del movimiento obrero y la izquierda, $\mathrm{n}^{\circ} 3$, Buenos Aires.

- (2007), Sobre los orígenes del sindicalismo revolucionario en Argentina, Buenos Aires: Ediciones CCC.

Bertolo, Maricel (1993), Una propuesta gremial alternativa: el sindicalismo revolucionario (1904-1916), Buenos Aires: CEAL.

- (2011), "Los primeros pasos de la negociación colectiva en la Argentina", Cuadernos del Ciesal, año 8, n 10, pp 71-95.

Bilsky, Edgardo (1987), La FORA y el movimiento obrero, tomos 1 y 2, Buenos Aires: CEAL.

Calello, Hugo, Miguel Murmis y Juan Carlos Marín (1969), "Un sindicalismo de tradición artesanal", en Torcuato S. Di Tella (comp.), Estructuras sindicales. Cuadernos de Investigación Social, Buenos Aires: Nueva Visión.

Caruso, Laura (2016a), Embarcados. Los trabajadores maritimos y la vida a bordo: sindicato, empresas y Estado en el puerto de Buenos Aires (18891921), Buenos Aires: Colección Archivos, Imago Mundi.

- (2016b), "Hombres a bordo: experiencia laboral y masculinidades en el mundo del trabajo marítimo en la primera posguerra", en Andrea Andújar et al., Vivir con lo justo: estudios de historia social del trabajo en perspectiva de género. Argentina, siglos XIX y XX, Rosario: Prohistoria.

- (2017), "La Unión del Marino: la prensa gremial marítima, una lectura obrera sobre la cuestión social, la ley y los derechos (1911-1928)", en Ricardo González Leandri y Juan Suriano (eds.), La cuestión social y sus itinerarios de difusión a través de las publicaciones periódicas argentinas, 1870-1930, Rockville: Global South Press.

D’Uva, Florencia (2011), "El sindicalismo revolucionario en la Semana Trágica: aportes para la comprensión del viraje hacia el reformismo de la FORA IX", en Trabajadores. Ideologias y experiencias en el movimiento obrero, Buenos Aires, pp. 104-127

Del Campo, Hugo (1986), El sindicalismo revolucionario (1905-1940), Buenos Aires: CEAL.

Doeswijk, Andreas (2013), Los anarco-bolcheviques rioplatenses (1917-1930), Buenos Aires: Cedinci.

Falcón, Ricardo y Alejandra Monserrat (2000), "Estado, empresas, trabajadores y sindicatos", en Ricardo Falcón (dir.), Nueva historia argentina, tomo VI: Democracia, conflicto social y renovación de ideas (1916-1930), Buenos Aires: Sudamericana.

Godio, Julio (1988), El movimiento obrero argentino (1910-1930). Socialismo, sindicalismo y comunismo, Buenos Aires: Legasa.

Horowitz, Joel (2001), "Cuando las elites y los trabajadores coincidieron: la resistencia al programa de bienestar patrocinado por el gobierno argentino, 1923-1924", Anuario IEHS, n 16, Tandil.

- (1995), "Argentina's failed general strike of 1921: a critical moment in the radical's relations with unions", en Hispanic American Historical Review, $\mathrm{n}^{\circ} 75$, pp. 57-80. 
Koppmann, Walter (2016), "Lucha de clases, formas de organización y estrategia politica del sindicalismo revolucionario en la industria de la madera y el mueble, Buenos Aires, 1915-1920", Izquierdas, n²6, IDEAUSACH, pp. 192-217.

Leyes, Rodolfo (2009), "La estrategia de sindicalización de la FORA IX en el oriente entrerriano (1917-1921)", Conflicto Social, n ${ }^{\circ} 2$.

Lobato, Mirta (2009), La prensa obrera, Buenos Aires: Edhasa.

López Cantera, Mercedes (2015), "Las estrategias del comunismo argentino en la mirada del nacionalismo reaccionario durante la década de 1930", Páginas, vol. $7, \mathrm{n}^{\circ} 15$, Rosario.

Marotta, Sebastián (1961), El movimiento sindical argentino. Su génesis y desarrollo, tomo II (1907-1920), Buenos Aires: Lacio.

Monserrat, M. Alejandra (2011), "La conflictividad obrera y el partido radical. Los trabajadores marítimos entre 1916 y 1930", en V. Cañete, F. Ríspoli, L. Ruocco y G. Yurkievich (comps.), Los puertos y su gente, pasado presente y porvenir. La problemática portuaria desde las ciencias sociales, Mar del Plata: Gesmar-UNMdP-Conicet.

Oliveira Jr, Moacir (1995), "Mudanças organizacionais e inovações tecnológicas: impactos sobre os padrões de relações de trabalho no Porto de Santos", Revista de Administração, São Paulo, vol. 30, n 3, p. 12-26.

Rock, David (1992), El radicalismo argentino (1890-1930), Buenos Aires: Amorrortu.

Suriano, Juan (2000), "La oposición anarquista a la intervención estatal en las relaciones laborales", en Juan Suriano (comp.), La cuestión social en Argentina, 1870-1943, Buenos Aires: La Colmena.

Texeira da Silva, Fernando (2003), Operarios sem patrões. Os trabalhadores da cidade de Santos no entreguerras, Unicamp, 2003.

$$
* * *
$$

Titulo: Federated, soldiers, and producers: revolutionary trade union militancy in the maritime sector (1910-1924)

Resumen: El sindicalismo revolucionario, sus ideas, prácticas y giros, fueron vitales en la experiencia del movimiento obrero en Argentina al despuntar el siglo XX. En la navegación marítima el sindicalismo tuvo un protagonismo determinante tanto para la experiencia de sus trabajadores como para la propia corriente. Este trabajo indaga la militancia sindicalista a bordo, sus prácticas y formas de organización y de acción, así como las nociones que las sustentaron. Esto busca dar cuenta tanto de las particularidades del sindicalismo como de sus aspectos compartidos, en relación a su estrategia político-sindical y las formas de desplegarla, particularmente a través de la federación, de ciertas nociones de masculinidad, del control del trabajo y de una particular defensa del derecho obrero.

Palabras clave: sindicalismo revolucionario - federación obrera maritima construcción gremial - control del trabajo - derechos laborales 


\begin{abstract}
Revolutionary sindicalism, its ideas, practices and turns, were vital in the experience of the labor movement in Argentina at the outset of the 20th century. In maritime navigation sindicalism had a decisive role both for the experience of its workers and for the current. This work investigates the syndicalim's militance on board, their practices and forms of organization and action, as well as the notions that sustained them. This seeks to give an account both of the particularities of sindicalism and of its shared aspects, in relation to its political-syndical strategy and the ways of deploying it, particularly through federation, of knowledge about masculinity, of labor control and of a defense of workers' rights.
\end{abstract}

Keywords: revolucionary sindicalism - maritime worker federation - labour policies - work control -labour rights

Recepción: 10 de enero de 2017. Aprobación: 4 de marzo de 2017. 